\title{
PENGGUNAAN COPEPOD Acartia sp. SEBAGAI MAKANAN PADA PEMELIHARAAN LARVA KERAPU BEBEK (Cromileptes altivelis)
}

\author{
Suko Ismi', Wardoyo', Ketut M. Setiawati', Jhon H. Hutapea', dan Titiek Aslianti'
}

\begin{abstract}
ABSTRAK
Salah satu kendala yang menyebabkan tingginya kematian larva pada pemeliharaan kerapu adalah besarnya ukuran pakan larva awal yang tidak sesuai dengan bukaan mulut larva, jenis, dan jumlah pakan yang diberikan. Penelitian ini bertujuan untuk mengetahui penggunaan nauplius $A$ cartia $\mathrm{sp}$. sebagai pakan awal pemeliharaan larva kerapu bebek. Wadah yang digunakan adalah tangki polikarbonat volume $200 \mathrm{~L}$ sebanyak sembilan buah yang diisi dengan larva yang baru menetas (D-0) 6000 ekor. Setelah larva membuka mulut pada hari ke tiga sampai hari ke delapan, larva diberi pakan: rotifer ( 6 ind $/ \mathrm{mL}$ ); nauplius Acartia sp. ( 3 ind $/ \mathrm{mL}$ ) dan rotifer ( 3 ind. $/ \mathrm{mL}$ ); serta nauplius Acartia sp. (6 ind./mL). Masing-masing perlakuan diulang tiga kali. Hasil penelitian menunjukkan bahwa larva yang diberi pakan nauplius Acartia sp. 3 ind. $/ \mathrm{mL}$ dan rotifer 3 ind. $/ \mathrm{mL}$ mempunyai sintasan dan panjang total $(12,89 \%$ dan $3,32 \mathrm{~mm}$ ) lebih baik dan berbeda nyata dengan perlakuan yang lain $(P<0,05)$, sedangkan larva yang diberi pakan rotifer 6 ind. $/ \mathrm{mL}$ dan nauplius Acartia sp. 6 ind. $/ \mathrm{mL}$ mempunyai sintasan dan panjang total yang tidak berbeda nyata $(P>0,05)$, yaitu masingmasing sintasan dan panjang total $(9,60 \%$ dan $3,06 \mathrm{~mm})$ dan $(7,29 \%$ dan $2,94 \mathrm{~mm})$
\end{abstract}

\section{ABSTRACT: Utilization of Copepod Acartia sp. on larval rearing of the polkadots grouper (Cromileptes altivelis). By: Suko Ismi, Wardoyo, Ketut M. Setiawati, Jhon H. Hutapea, and Titiek Aslianti.}

The main problem of high mortality in larval rearing of grouper is caused by small mouth opening size, as well as unsuitable size, quantity and kind of feed. The purpose of this experiment was to determine the utilization of nauplii of Acartia sp. as an initial food for grouper larvae. The experiment was carried out using nine polycarbonate tanks of $200 \mathrm{~L}$ capacity, filled with 6,000 newly hatched larvae (D-0). After the mouth opened on D-3 to D-8, the larvae were fed with rotifer (6 ind.I $\mathrm{mL}$ ): Acartia sp. nauplii (3 ind. $/ \mathrm{mL}$ ) and rotifer (3 ind. $/ \mathrm{mL}$; and Acartia sp. nauplii (6 ind. $/ \mathrm{mL}$ ) as treatments. The treatments were replicated three times.

The results showed that survival rate and total length of the larvae fed with Acartia sp. nauplii (3 ind. $/ \mathrm{mL}$ ) and rotifer (3 ind. $/ \mathrm{mL}$ ) were $12.89 \%$ and 3.32 were significantly higher $(P<0.05)$ than those of the other treaments. However, feed treatments with rotifer ( 6 ind. $/ \mathrm{mL}$ ) and Acartia nauplii ( 6 ind. $/ \mathrm{mL}$ ) have surivival rate dan total length were not significantly different $(P>0.05)$, were survival rate dan total length $(9.60 \%$ and $3.06 \mathrm{~mm})$ and $(7.29 \%$ and $2.94 \mathrm{~mm})$ respectively.

KEYWORDS: Cromileptes altivelis, Acartia sp. nauplii, rotifer.

\section{PENDAHULUAN}

Kerapu bebek adalah salah satu di antara jenis ikan laut yang mempunyai nilai ekonomis tinggi. Ikan ini selain dibudidayakan untuk konsumsi juga pada waktu masa yuwana dipakai sebagai ikan hias. Produksi massal benih kerapu bebek sudah dapat dilakukan, akan tetapi sintasannya sampai yuwana masih sangat rendah. Tingkat kematian yang tinggi sering terjadi pada stadia awal yaitu umur 4-8 hari. $\mathrm{Hal}$ ini antara lain disebabkan pergantian sumber nutrisi dari dalam (endogenous) ke nutrisi dari luar (exogenous) (Hunter, 1980; Roger \& Westin, 1981). Beberapa penelitian mengenai pemeliharaan larva kerapu yang telah dilakukan antara lain terhadap Epinephelus akaara (Ukuwa et al., 1966; Tseng \& Ho, 1979), E amblycephalus (Tseng \& Chan, 1985), E. salmoides (Hamanto et al., 1986; Huang et al.,1986; Lin et al., 1986), E. tauvina (Hussain et al. 1975; Chen et al., 1977; Hussain \& Higuchi, 1980) E. fuscoguttatus (Mayunar, 1991; Waspada, 1991) Hasil penelitian tersebut menyatakan bahwa tingkat kematian tertinggi terjadi pada stadia awal larva Menurut Hussain \& Higuchi (1980) serta Doi et al. (1994) kematian tersebut disebabkan karena ukuran pakan awal yang diberikan lebih besar dari ukuran bukaan mulut larva, sehingga larva mengalami kesulitan untuk menelan mangsanya. Hal serupa juga terjadi pada larva ikan laut yang lain seperti kakap merah (Lutjanus argentimaculatus) yang mempunyai bukaan mulut (0,166-0,188 mm) (Doi et al., 1997). Ikan kerapu bebek yang mempunyai ukuran bukaan mulut 135 mm (Slamet et al., 1996) dan diberi pakan awal hanya rotifer ternyata sintasannya masih rendah. Mengacu kepada beberapa penelitian tersebut maka pada penelitian ini dicoba untuk

Peneliti pada Loka Penelitian Perikanan Pantai Gondol 
menggunakan nauplius dari Acartia sp. untuk pakan awal pada pemeliharaan larva kerapu bebek. Nauplius Acartia sp. pada stadia tertentu mempunyai ukuran yang lebih kecil dari rotifer, yaitu pada nauplius-1 sampai nauplius-6 ukurannya berkisar 100-200 $\mathrm{mm}$ dan rotifer tipe SS mempunyai ukuran 146-150 $\mathrm{mm}$.

\section{BAHAN DAN METODE}

Percobaan penggunaan copepoda Acartia sp. pada pemeliharaan larva kerapu bebek menggunakan tangki polikarbonat $200 \mathrm{~L}$ sebanyak sembilan buah. Untuk mempertahankan suhu air $27^{\circ} \pm 1^{\circ} \mathrm{C}$, tangki polikarbonat diletakkan di dalam tiga waterbath

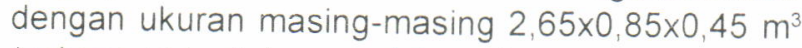
(volume \pm 1 ton) dengan sistem air mengalir. Masingmasing tangki diisi larva 6.000 ekor. Larva yang mulai membuka mulut pada hari ke tiga sampai hari ke delapan setiap hari diberi pakan sesuai dengan perlakuan sebagai berikut:
A. Rotifer 6 ind. $/ \mathrm{mL}$
B. Nauplius Acartia sp. 3 ind./mL dan rotifer 3 ind./ $\mathrm{mL}$.
C. Nauplius Acartia sp. 6 ind. $/ \mathrm{mL}$

Rotifer yang dipakai adalah tipe SS. Untuk pemberian pakan setiap hari dihitung jumlah sisa pakan di dalam tangki pemeliharaan guna penyesuaian pakan yang ditambahkan. Percobaan menggunakan rancangan acak lengkap dengan tiga ulangan. Parameter yang diamati adalah sintasan larva pada akhir percobaan (hari ke-8). Lima ekor larva diambil setiap hari untuk diamati pertumbuhannya dengan mengukur panjang total (TL), juga dilakukan identifikasi jenis dan jumlah pakan yang dikonsumsi oleh larva. Lebar mulut diukur dengan melihat larva dari bagian punggung (dorsal view) kemudian diukur lebar bagian mulut atas (karena untuk bukaan mulut ukurannya tidak pasti, tergantung lebarnya ikan membuka mulut waktu pengamatan sehingga nilainya tidak tetap). Parameter kualitas air yang meliputi pH, DO, suhu. salinitas, amonia dan nitrit diukur setiap hari pada pukul 09.00 pagi

\section{HASIL DAN BAHASAN}

Pada akhir percobaan, larva yang diberi pakan awal campuran nauplius Acartia sp. dan rotifer memberikan hasil sintasan dan panjang total yang terbaik $(12,89 \%$ dan $3,32 \mathrm{~mm})$ yang berbeda nyata $(P<0,05)$ dibandingkan dengan pada perlakuan yang lain (Tabel 1). Larva yang diberi pakan awal hanya rotifer mempunyai sintasan dan panjang total $(9,60 \%$ dan $3,06 \mathrm{~mm})$ tidak berbeda $(P>0,05)$ dengan larva yang hanya diberi pakan nauplius Acartia sp. (7,29\% dan 2,94 mm). Hasil pengamatan panjang total larva kerapu bebek selama percobaan dapat dilihat pada Gambar 1

Jika dilihat dari sintasan larva, kematian pada stadia awal sangat tinggi. Salah satu penyebabnya adalah ketidakmampuan larva untuk menangkap makanan dari luar, karena pada hari ke tiga saat larva mulai buka mulut gerakan larva masih kurang aktif untuk mengejar makanan, sehingga larva gagal untuk mendapatkan makanan. Seperti pendapat Kohno et al. (1990), tingginya kematian dalam pemeliharaan larva ikan kerapu adalah kegagalan dan keterlambatan larva untuk memulai makan dan rendahnya daya pemangsaan. Sedangkan menurut Blaxter (1969), keberhasilan dan kegagalan dalam pemangsaan larva tergantung pada kekuatan mengejar pakan yang ada di sekitarnya. Pada stadia larva ikan laut umumnya, daya lihat adalah sangat penting untuk aktivitas mencari pakan (Hunter, 1980: Kawamura \& Ishida, 1984). Sedangkan Blaxter

Tabel 1. Rata-rata sintasan dan panjang total larva kerapu bebek (Cromileptes altivelis) dengan pemberian pakan awal yang berbeda.

Table 1. Average survival rate and total length of polkadots grouper (Cromileptes altivelis) larvae at different initial feeding.

\begin{tabular}{lcc}
\hline $\begin{array}{c}\text { Perlakuan } \\
\text { Treatment }\end{array}$ & $\begin{array}{c}\text { Panjang total } \\
\text { Total length } \\
(\mathbf{m m})\end{array}$ & $\begin{array}{c}\text { Sintasan } \\
\text { Survival rate } \\
(\%)\end{array}$ \\
\hline A (Rotifer) & $3.32 \pm 0.17^{\mathrm{a}}$ & $12.89 \pm 0.35^{\mathrm{a}}$ \\
B (Rotifer + N. acartia) & $3.06 \pm 0.17^{\mathrm{b}}$ & $9.60 \pm 0.29^{\mathrm{b}}$ \\
C (Nauplius acartia) & $2.94 \pm 0.16^{\mathrm{b}}$ & $7.29 \pm 0.27^{\mathrm{b}}$ \\
\hline
\end{tabular}

Nilai dalam kolom yang diikuti huruf superskrip yang sama tidak berbeda nyata (Values in column followed with the same superscript are not significantly different) $(P<0.05)$ 


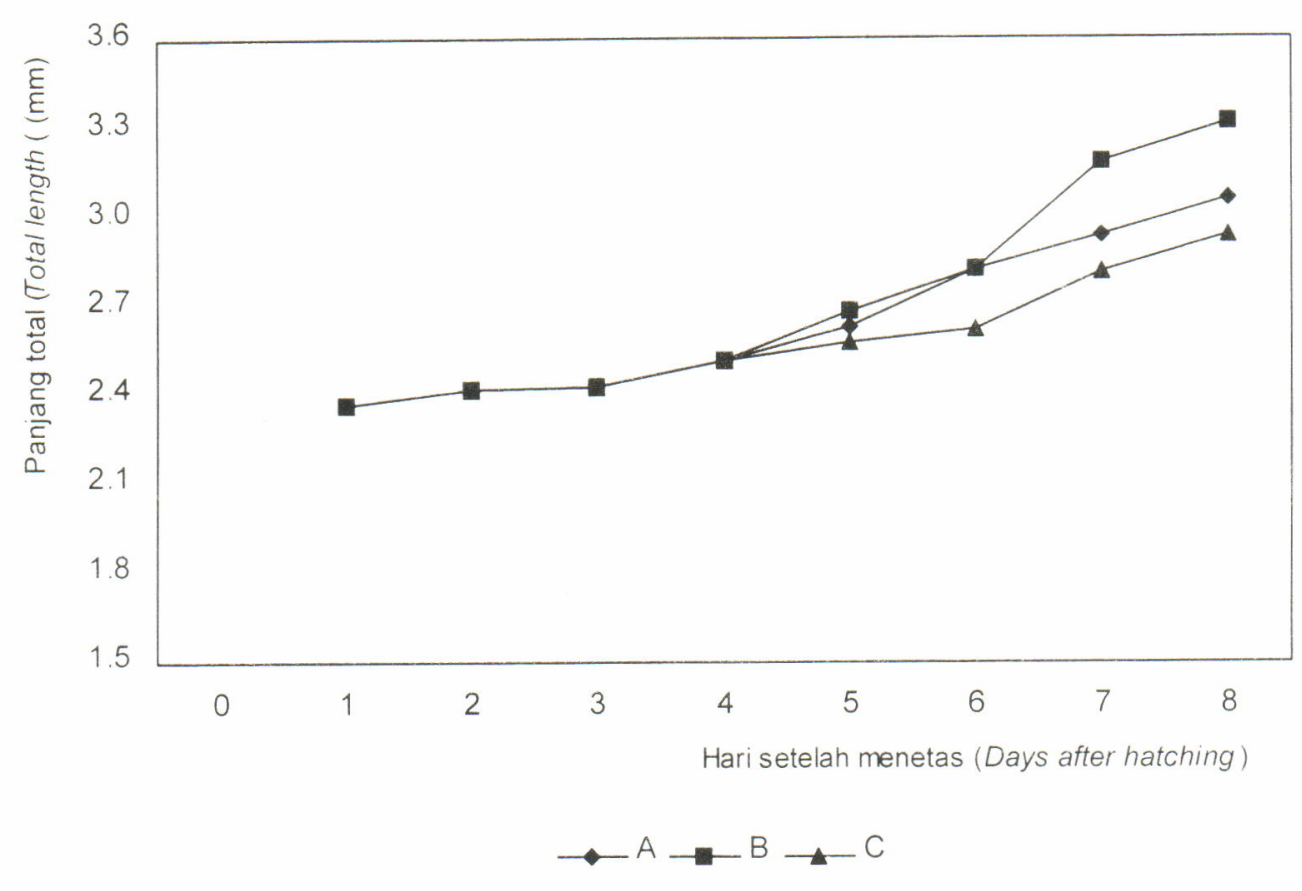

Gambar 1. Panjang total ( $\mathrm{mm}$ ) larva kerapu bebek (Cromileptes altivelis) dengan pemberian pakan awal yang berbeda ( A. rotifer; B. rotifer + nauplius Acartia sp.; C nauplius Acartia sp.).

Figure 1. Total length $(\mathrm{mm})$ of polkadots grouper (Cromileptes altivelis) larvae given different initial feeds (A. rotifer; B. rotifer + Acartia sp. nauplius; C. Acartia sp. nauplius).

(1980) mengemukakan bahwa pada stadia larva yang mempunyai ukuran mata kecil, jarak penglihatannya pendek, kurang tajam, dan kekontrasannya rendah. Selain itu ukuran lebar mulut atas yang berhubungan dengan lebar bukaan mulut larva berdasarkan pengamatan pada percobaan ini relatif kecil yaitu pada hari ke-3: $\pm 143 \mathrm{~mm}$, hari ke-4: $\pm 152 \mathrm{~mm}$, hari ke-5: $\pm 170 \mathrm{~mm}$, hari ke- $6: \pm 190 \mathrm{~mm}$, hari ke-7: $\pm 210 \mathrm{~mm}$ dan hari ke-8: $\pm 232 \mathrm{~mm}$, sedangkan rotifer tipe SS yang diberikan mempunyai ukuran 145$150 \mathrm{~mm}$ dan ukuran nauplius Acartia sp. pada stadia N-1: $100 \mathrm{~mm}, \mathrm{~N}-2: 120 \mathrm{~mm}, \mathrm{~N}-3: 150 \mathrm{~mm}, \mathrm{~N}-4$ : 170 mm, N-5: 200 mm dan N-6 : 230 mm. Karena itu makanan yang tersedia pada stadia tertentu ukurannya relatif lebih besar jika dibanding dengan ukuran bukaan mulut larva. Seperti pendapat Doi et al. (1994), kematian tertinggi pada larva umumnya terjadi pada stadia awal yang disebabkan karena ukuran pakan awal yang diberikan tidak sesuai dengan bukaan mulut larva, di samping menurut Kohno et al. (1990) larva ikan kerapu mempunyai daya tingkat pemangsaan yang rendah. Hasil pengamatan isi perut larva dari hari ke tiga sampai hari ke delapan dapat dilihat pada Tabel 2

Dari Tabel 2 terlihat jumlah isi perut pada larva dengan pakan campuran nauplius Acartia sp. dan rotifer jika dijumlahkan lebih banyak dari jumlah isi perut pakan yang hanya rotifer atau hanya nauplius Acartia sp. saja. Nampaknya terhadap pakan campuran, larva mempunyai alternatif memilih dan lebih banyak makan.

Dari Tabel 3 nampak sisa pakan rotifer setiap hari masih dalam jumlah yang mencukupi untuk persediaan pakan sehingga tidak perlu menambah rotifer dari luar. Hal ini disebabkan rotifer dapat berkembang selama pemeliharaan larva, sedangkan sisa pakan dari nauplius Acartia sp. hanya sedikit bahkan habis, sehingga untuk persediaan pakan harus ditambahkan dari luar sesuai dengan jumlah yang telah ditetapkan. Sifat Acartia sp tidak bisa berkembang dengan cepat mengingat siklus hidupnya yang panjang (5-6 hari) dengan beberapa tingkat stadia.

Pemberian pakan campuran nauplius Acartia sp. dan rotifer menghasilkan sintasan dan pertumbuhan yang lebih tinggi, karena selain dapat memenuhi jumlah, jenis, dan ukuran, juga mempunyai nutrisi yang lebih baik. Menurut Watanabe (1978) asam lemak Eikosapentaenoat 20:5n3 dan Dokosaheksaenoat 22:6n3 yang merupakan asam lemak tidak jenuh rantai panjang (HUFA) terbukti esensial bagi ikan laut. Selanjutnya dikatakan bahwa rotifer yang 
Tabel 2. Jumlah isi perut (ind.) larva kerapu bebek dengan pakan awal yang berbeda

Table 2. Total number of stomach content (ind) of polkadot grouper larvae given different initial feeds.

\begin{tabular}{cccccccc}
\hline \multirow{2}{*}{$\begin{array}{c}\text { Perlakuan } \\
\text { Treatment }\end{array}$} & $\begin{array}{c}\text { Pakan (Food) } \\
\text { (ind.) }\end{array}$ & \multicolumn{7}{c}{$\begin{array}{c}\text { Umur larva (hari) } \\
\text { Larval age (day) }\end{array}$} \\
\cline { 3 - 8 } & & $\mathbf{3}$ & $\mathbf{4}$ & $\mathbf{5}$ & 6 & $\mathbf{7}$ & $\mathbf{8}$ \\
\hline \multirow{2}{*}{$\mathrm{A}$} & Rotifer & $1.0 \pm 0.31$ & $4.3 \pm 1.13$ & $5.7 \pm 0.98$ & $6.7 \pm 1.45$ & $7.3 \pm 0.93$ & $7.7 \pm 0.72$ \\
B & N. Acartia & $2.0 \pm 0.34$ & $3.7 \pm 0.97$ & $4.7 \pm 0.45$ & $5.3 \pm 0.79$ & $5.7 \pm 0.45$ & $5.7 \pm 0.47$ \\
& Rotifer & $1.7 \pm 0.41$ & $2.7 \pm 0.45$ & $4.3 \pm 0.14$ & $4.7 \pm 0.53$ & $5.3 \pm 0.76$ & $6.0 \pm 1.45$ \\
C & N. Acartia & $1.7 \pm 0.29$ & $3.7 \pm 0.12$ & $4.0 \pm 0.97$ & $5.3 \pm 0.98$ & $6.0 \pm 1.02$ & $6.3 \pm 0.41$ \\
& & & & &
\end{tabular}

Untuk detail lihat teks (See text for details)

Tabel 3. Jumlah sisa pakan (ind./mL) dalam tangki pemeliharaan larva kerapu bebek dengan pakan awal yang berbeda.

Table 3. Total number of feed remains (ind. $/ \mathrm{mL}$ ) of polkadot grouper larvae given different initial feeds.

\begin{tabular}{clccccc}
\hline \multirow{2}{*}{$\begin{array}{c}\text { Perlakuan } \\
\text { Treatment }\end{array}$} & $\begin{array}{c}\text { Pakan (Food) } \\
\text { (ind./mL) }\end{array}$ & \multicolumn{5}{c}{$\begin{array}{c}\text { Umur larva (hari) } \\
\text { Larval age (day) }\end{array}$} \\
\cline { 3 - 7 } & & $\mathbf{4}$ & $\mathbf{5}$ & $\mathbf{6}$ & $\mathbf{7}$ & $\mathbf{8}$ \\
\hline A & Rotifer & 10.7 & 7.3 & 4.7 & 7.3 & 7.0 \\
B & N. Acartia & 1.0 & 0.7 & 0.3 & 0.0 & 0.0 \\
& Rotifer & 7.3 & 5.3 & 1.7 & 8.0 & 6.3 \\
C & N. Acartia & 1.3 & 0.3 & 0.0 & 0.0 & 0.0 \\
\hline
\end{tabular}

Untuk detail lihat teks (See text for details)

diberi pakan Chlorella sp. mempunyai kandungan $20: 5 n 3$ sebesar $24,1 \%$ dan $22: 6 n 3$ sebesar $0,9 \%$ sedangkan Acartia sp. mengandung 20:5n3 sebesar $20,1 \%$ dan $22: 6 n 3$ sebesar $28,6 \%$. Berdasarkan hal tersebut, pemberian pakan campuran nauplius Acartia sp. dan rotifer mempunyai EPA dan DHA yang lebih tinggi sehingga nutrisinya lebih baik daripada hanya satu jenis pakan saja. Walaupun demikian sampai saat ini kultur Acartia sp. untuk memasok pakan secara berkesinambungan masih sulit dilakukan.

Kualitas air selama penelitian pada masing-masing perlakuan masih dalam batas yang layak untuk pemeliharaan larva kerapu yaitu suhu $\left(26,4^{\circ}-28,7^{\circ} \mathrm{C}\right)$; $\mathrm{pH}(8,2-8,38)$; salinitas (34-35 ppt); DO $(4,6-5,4 \mathrm{mg} /$ L); nitrit $(0,012-0,74 \mathrm{mg} / \mathrm{L})$, dan amonia $(0,12-0,71 \mathrm{mg} /$ L).

\section{KESIMPULAN}

Pemberian pakan awal pada pemeliharaan larva kerapu bebek berupa campuran nauplius Acartia sp. dan rotifer mempunyai sintasan dan panjang total lebih baik dibandingkan dengan larva yang diberi pakan awal hanya rotifer atau hanya nauplius Acartia sp.

\section{DAFTAR PUSTAKA}

Blaxter, J.H.S. 1969. Development of egg and larvae. III Hoar, W.S. and Randale, D.J. (eds). Fish physiology Vol. III. Reproduction and growth, Biolumenesence. pigments and poisons. Academic Press New York and London. 177-252.

Blaxter, J.H.S. 1980. Vision and the feeding of fishes $/ \mathrm{n}$ Bardach, J.E., Magnuson, J.J., May, R.C. and Reinkart, J.M. (eds)., Fish behaviour and its use in the capture and culture of fishes. ICLARM Conference Proceeding. p. 375-387.

Chen, F.Y., Chow, M., Chao, T.M., and Lim, R. 1977. Artificial spawning and larval rearing of the grouper. Epinephelus tauvina (Forskal) in Singapore J. Prim. Ind., 5:1-21.

Doi, M., Ohno, A., Taki, Y., Singhagraiwan, T., and Kohno, H. 1997. Nauplii of the Calanoid copepod, Acartia sinjiensis as an initial food organism for larval red Snaper, Lutjanus argentimaculatus. Japan Aquacult. Soc., 45(1):31-40

Doi, M., Singhagraiwan, S., Singhagraiwan, T., Kitade, M., and Ohno, A. 1994. Culture of Calanoid Copepod, Acartia sinjiensis, in outdoor tanks in the tropics. Thai Mar. Fish. Res. Bull., 5 :27-36 
Hamanto, S., Manabe, S., Kasuga, A., and Nasoka, K. 1986. Spawning and early life history of grouper Epinephelus salmoides (Lacepede) in laboratory. Tech. Rep. Farm. Fish., 15:143-155.

Huang, T.S., Lin, K.J., Yen, C.L., Lin, C.Y., and Chen, C.L. 1986. Experiment on the artificial propagation of black spotted grouper, Epinephelus salmoides (Lacepede)-I, hormone treatment, ovulation of spawner and embrionic development. Bull. Taiwan Fish. Res. Inst., 40:241-248

Hunter, J.R. 1980. The feeding behavior and ecology of marine fish larvae. In, Fish behavior and its use in the capture of fishes. Bardach, J.E., Magnuson, J.J., May, R.C., and Reinhart, M. (eds). ICLARM, Manila, Philipines: 287-330

Hussain, N., Saif, M., and Ukuwa, M. 1975. On the culture of Epinephelus tauvina (Forskal). Kuwait Institute for Scientific Research, Kuwait. $12 \mathrm{pp}$

Hussain, N. and Higuchi, M. 1980. Larval rearing and development of the brown spotted grouper, Epinephelus tauvina (Forskal). Aquaculture, 19:339-350.

Kawamura, G. and Ishida, K. 1980. Changes in sense organ morphology and behavior with growth in the flounder, Paralichthys olivaceus. Bull. Jap. Soc. Sci. Fish. 51(2): 155-165

Kohno, H., Diani, S., Sunyoto, P., Slamet, B., and Imanto, P.T. 1990. Early development events associated with change over of nutrient sources in the grouper, Epinephelus fuscoguttatus larvae. Bulletin Penelitian Perikanan. 1: 41-64

Lin, K.J., Yen, C.L., Huang, T.S., Liu, C.Y., and Chen, C.L. 1986. Experiment of fry nursing of Epinephelus salmoides (lacepede) and its morphological study. Bull. Taiwan Fish. Res. Inst., 40:219-240.
Mayunar, Redjeki, S., dan Murtiningsih, S. 1991. Pemeliharaan larva kerapu macan. Epinephelus fuscoguttatus dengan berbagai frekuensi pemberian ransum rotifer. Jurnal Penelitian Budidaya Pantai. 7(2):35-41

Roger, B.A. and Westin, D.T. 1981. Laboratory studies on effect of temperature and delayed initial feeding on development of striped bass larvae. Trans. Am. Fish Soc., 110:100-110

Slamet, B.,Tridjoko, Prijono, A., Setiadharma, T., dan Sugama, K. 1996. Penyerapan nutrisi endogen, tabiat makan dan perkembangan morfologi larva kerapu bebek (Cromileptes altivelis). Jurnal Penelitian Perikanan Indonesia 2(2):13-21.

Tseng, W.Y. and Chan, K.F. 1985. On the larval rearing of the white spotted grouper, Epinephelus ablycephalus (Bleeker), with a description of larval development. J. Word Maricult. Soc., 16:114-126

Tseng, W.Y. and Ho, S.K. 1979. Eggs development and early larval rearing of red grouper (Epinephelus akaara Temminck \& Schlegel). Quart. J. Taiwan Mus., 32:209219.

Ukuwa, M., Higuchi, M., and Mito, S. 1966. Spawning habit and early life history of a rerranid fish. Epinephelus akaara (Temminck \& Schlegel). Japan J. Ichthyol.. 13:156-161.

Waspada, Setiawan, Y., dan Rodif, M. 1991. Pengaruh berbagai peningkatan gizi rotifer, Brachionus plicatilis terhadap pertumbuhan dan kelangsungan hidup larva ikan kerapu macan, Epinephelus fuscoguttatus. Jurnal Penelitian Budidaya Pantai, 7(2):57-66.

Watanabe, T. 1978. Nutrional quality of living feeds used in seed production of fish. Proc. 7th Japan. Soviet Joint Symposium. Aquaculture. 7 pp. 